\title{
INTERFERENCE MEASUREMENTS IN THE FIRST SPECTRA OF NEON, ARGON, AND KRYPTON BETWEEN 4812 AND $3319 \mathrm{~A}^{1}$
}

\author{
By Curtis J. Humphreys
}

\section{ABSTRACT}

Wave-length measurements in the first spectra of neon, argon, and krypton have been made, using Fabry-Perot interferometers with aluminized quartz plates and etalons of $3,7.5,8,8.4,15,20$, and $25 \mathrm{~mm}$ length. The wave lengths have been determined relative to the adopted International Wave-Length Standards in $\mathrm{Kr} \mathrm{I}$. All but three of the 30 possible $1 s-3 p$ lines of Ne I are intense enough to permit interference measurements. This group lies between 3754 and $3370 \mathrm{~A}$.

New measurements are reported of the intense $1 s-3 p$ group of A I, previously measured relative to $\mathrm{Ne}$ and $\mathrm{Cd}$ standards, but here, for the first time, relative to $\mathrm{Kr}$ I. The argon measurements also include 17 ultraviolet lines, the last at $3319 \mathrm{~A}$.

Measurements in Kr I comprise 30 lines of wave lengths shorter than $4274 \mathrm{~A}$, the limit of previous work. An additional $f$-type series has been revealed. It is now possible, by interference methods, to fix the various $p$-series of $\mathrm{Kr}$ I to four members. In addition, measurements were made of seven krypton lines between 4812 and $4302 \mathrm{~A}$, not included among the International Wave-Length Standards of 1935 .

The short wave-length limit of these measurements is set by the intensity decrement of lines approaching the series limits, the $1 s$-levels $\left({ }^{1} \mathrm{P},{ }^{3} \mathrm{P}\right)$ of the noblegas spectra. It is expected that the more-intense lines will prove useful as wavelength standards. The neon group is the most promising in this respect. The possibility of a pressure effect in higher series lines in neon and argon has been investigated to a limited extent by comparing wave lengths obtained with Geissler tubes filled with gas to "low" and "high" pressures. Without drawing general conclusions, it may be stated that no such effect was observed for the $1 s-3 p$ lines of neon, but that the use of argon tubes filled to $20-\mathrm{mm}$ pressure led to very marked line broadening and some evidence of pressure displacement.

Construction of arrays of term combinations indicates a relative accuracy of the measurements of the same degree as that obtained in the case of the adopted secondary standards.

\section{CONTENTS}

I. Introduction

II. Discussion of pressure effect and isotopic hyperfine structure

III. Experiments_..... 21

IV. Results $\ldots$

1. Neon

2. Argon

3. Krypton

V. References

\section{INTRODUCTION}

The spectra of the noble gases, particularly neon and krypton, have found considerable application as sources of wave-length stand-

1 A preliminary report of these measurements was given at the Washington meeting of the American Physical Society, April 1937, Phys. Rev. 51, 1018A (1937). 
ards for spectroscopic measurements and metrology. In 1935 the International Astronomical Union, which sponsors the specification and adoption of such standards, adopted wave-length values of 20 lines each of neon and krypton as international secondary standards $[1]^{2}$. The neon and krypton scales are regarded as agreeing with that of the primary standard, the red line of cadmium (6438.4696 A), to within 1 part in $50,000,000$.

The noble-gas spectra have been the subject of numerous investigations at this Bureau, and an extensive series of interference measurements has been made. A paper by Meggers and the author [2], published in 1934, reported interference measurements in $\mathrm{He} \mathrm{I}, \mathrm{Ne} \mathrm{I}$, A I, Kr I, and Xe I, between 10830 and $3948 \mathrm{~A}$, and included results of previous work for comparison. It was stated there that "Geissler tubes containing noble gases are at present the most convenient and reproducible sources of secondary standards of wave length." In the same paper, the relative merits of the various noble gases, from the point of view of suitability as sources of wave-length standards, were discussed. This discussion, which included consideration of limiting orders of interference, reversibility, and isotopic hyperfine structure, need not be repeated, although some further discussion of the effect of the presence of isotopic hyperfine structures on the measurement of interference patterns will be given.

The purpose of the present investigation was twofold: First, to extend the interference measurements into the ultraviolet region, where standards are greatly needed, and also to remeasure certain visible lines, particularly in case of argon, for which additional independent observations are desirable.

Unfortunately, the number of ultraviolet noble-gas lines of sufficient intensity for interference measurements is small. Examination of the term values [3] shows why this must be true. The same discussion applies in essentials to $\mathrm{Ne}$ I, $\mathrm{A} \mathrm{I}, \mathrm{Kr}$ I, and $\mathrm{Xe}$. . The combinations with the normal state, $s^{2} p^{6}{ }^{1} \mathrm{~S}_{0}$ all lie in the extreme ultraviolet observable only with vacuum spectrographs.

The $1 s-2 p$ combinations (Paschen notation [4]) comprise the most intense visible and infrared lines of the noble-gas spectra. The $1 s-3 p$ lines are all ultraviolet in neon, mostly visible in argon and krypton, and all visible in xenon. (Series converging to the $2 p$ levels are all visible or infrared.) The available ultraviolet lines are limited therefore to higher series members of the $1 s-n p$ type and a few combinations with $f$-type levels. The short wave-length limit to the observations is set by the intensity decrement of lines approaching the series limits, the $1 s$-levels $\left({ }^{1} \mathrm{P},{ }^{3} \mathrm{P}\right)$. The first spectra of the noble gases contain no lines between the $1 s_{5}$ limits and the extreme ultraviolet combinations. These $1 s_{5}$ limits have been evaluated as follows: $\mathrm{Ne}, 39887.6 \mathrm{~cm}^{-1}$ or $2506.3 \mathrm{~A} ; \mathrm{A}, 33767.7 \mathrm{~cm}^{-1}$ or $2943.1 \mathrm{~A}$; $\mathrm{Kr}$, $32943.2 \mathrm{~cm}^{-1}$ or $3034.6 \mathrm{~A}$; and $\mathrm{Xe} 30766.4 \mathrm{~cm}^{-1}$ or $3249.4 \mathrm{~A}$.

\section{DISCUSSION OF PRESSURE EFFECT AND ISOTOPIC HYPERFINE STRUCTURE}

A possible objection to the use of ultraviolet noble-gas lines as standards is that inasmuch as they involve combinations of high

2 Numbers in brackets refer to publications listed at the end of this paper. 
levels they may be more susceptible to pressure effect than lines in the less refrangible part of the spectrum.

In 1936, Jackson [5] reported determinations relative to the cadmium primary standard of 47 visible and ultraviolet krypton lines between 6456 and $3424 \mathrm{~A}$, including 14 of the ultraviolet lines measured in this investigation. He compared results from tubes filled to pressures of $0.1,4,10$, and $20 \mathrm{~mm}$ of mercury. His results indicated pressure displacement proportional to the square of the pressure for any given term. The pressure shift was also found to be dependent only on the principal quantum number of the terms, within experimental error. It was concluded that the maximum operating pressures for the various krypton series, without introducing pressure shifts sufficient to affect interferometer comparisons by $0.0001 \mathrm{~A}$, were as follows: for $1 s-2 p, 10 \mathrm{~mm}$; for $1 s-3 p, 4 \mathrm{~mm}$; and for $1 s-4 p$, less than $1 \mathrm{~mm}$. The $1 s-3 p$ lines of neon which were observed in this investigation are analogous in origin to the blue krypton group, 4502 to $4273 \mathrm{~A}$, comprising most of the adopted krypton secondary standards. One would expect the pressure effect to be of about the same magnitude for the corresponding transitions. It seems certain that no difficulty with pressure effect will be experienced if an operating pressure of the order of $1 \mathrm{~mm}$ is specified. The matter will be referred to again in connection with the account of our experimental work.

The effect of isotopic hyperfine structure on the wave-length measurements in neon has been the subject of considerable discussion, and it is felt that it can be treated in some detail here. The two abundant isotopes of neon are of atomic weight 20 and 22, in proportions of about 9 to 1 . In the observed spectrum each neon line should have a close satellite due to isotope 22 . Unless, however, the source is cooled by use of liquid air, this pattern is usually not resolved and the measured wave length will be that of the blend. The most probable comparator setting would be on the centroid of the pattern. Ritschl and Schober [6] have recently measured the isotope separation for all the strong neon lines, permitting a calculation of the displacements of a large number of terms.

Most of the $1 s-2 p$ lines have a separation of about $55 \times 10^{-3} \mathrm{~cm}^{-1}$, whereas in the case of the $1 s-3 p$ lines, it is generally about $85 \times$ $10^{-3} \mathrm{~cm}^{-1}$; the difference being due to the smaller displacement of higher $p$ terms. It is apparent, therefore, that measurements of $1 s-3 p$ lines will be affected by isotope displacements to a slightly greater degree than those of $1 s-2 p$ lines. When interference patterns are measured, the effect of an unresolved satellite upon the apparent wave length depends upon the order of interference. The experience of various observers was discussed at the 1935 meeting of the IAU [7], and, in adopting the recommended standards in neon, it was agreed to specify "that they apply only to the conditions under which they were determined, viz., with interferometers of high resolving power but etalons not exceeding about $4 \mathrm{~cm}$."

The following discussion based on the geometry of an interference pattern from a Fabry-Perot interferometer is intended to account for the observed results, in particular why a separation of $4 \mathrm{~cm}$ is some- 
what critical for the neon case. The order of interference is given by

$$
P=\frac{2 e}{\lambda} \cos \theta,[8]
$$

where $e$ is the separation (length of etalon) and $\theta$ is the angular separation of the fringe corresponding to $P$ from the optical axis. The dispersion is given by the partial derivative

$$
\frac{\delta \theta}{\delta \lambda}=-\frac{1}{\sin \theta} \frac{P}{2 e}
$$

Inasmuch as the ratio $P / 2 e$ is constant, it follows that for a given $\theta$ the separation of a satellite from a principal component will be constant. The angular separation of orders will, however, differ with retardation, and while a satellite will maintain its separation from the principal component of the same order, it will change its position with respect to the principal component of next higher or lower order. Figure 1 illustrates the interference pattern of a neon

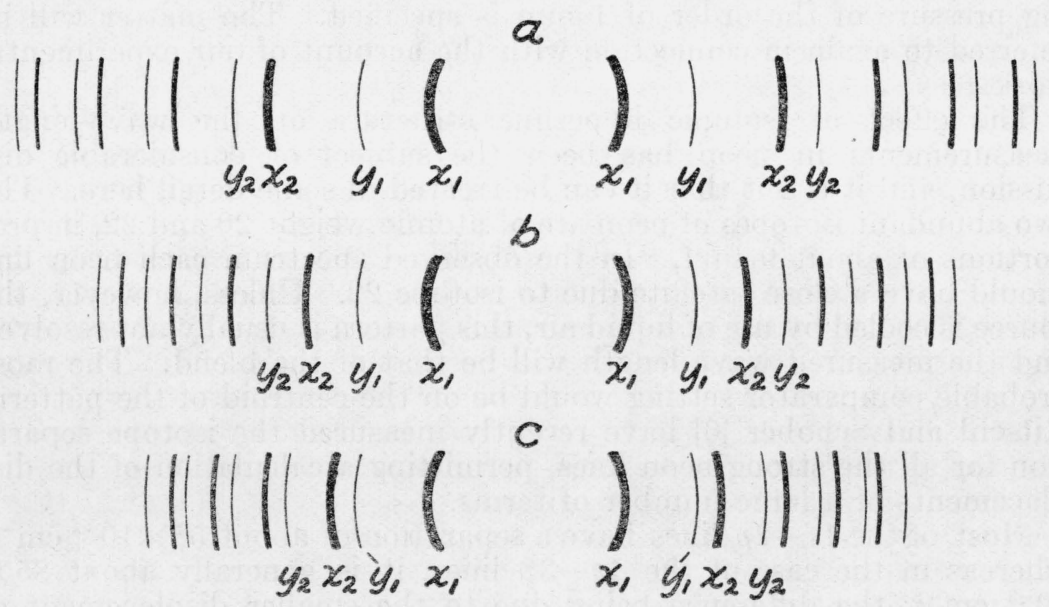

FIGURE 1.-Effect of increasing interference path on hyperfine structure pattern consisting of two components, the fainter being of shorter wave length.

line for three different retardations. The faint line due to $\mathrm{Ne} 22$ is always of shorter wave length than the heavy line due to $\mathrm{Ne} 20$. It is first assumed that the pattern is resolved completely.

Case $a$ represents the pattern for a small separation. Case $b$ shows the situation when the satellite is just midway between the principal components of successive orders. In case $c$, with increasing separation, the satellite $y_{1}$, although of the same order as $x_{1}$, is actually nearer to $x_{2}$. Suppose that the patterns are not resolved. For case $a$, the settings will fall outside the principal component, giving a result slightly smaller than if the setting were on the heavy fringe. For case $b$, the settings will be on the heavy components, so that the wave lengths will be those of $\mathrm{Ne} 20$.

For case $c$, the settings will be inside and the apparent wave lengths will be greater. Another possibility is the superposition of the light 
and heavy fringes which will occur for twice the separation corresponding to case $b$. This will give the same result as for $b$.

We see then, that there will be a cycle of increasing and diminishing apparent wave lengths. We are hardly interested in more than one phase of it, however, for that will represent the maximum path over which neon interferences can occur. Case $b$ will occur for the majority of the $1 s-2 p$ lines with an etalon of a little less than $5 \mathrm{~cm}$. If we choose one of the $1 s-3 p$ lines, the critical value will be slightly less than $3 \mathrm{~cm}$. This discussion agrees with the experience of observers that the neon red lines have apparent wave lengths somewhat smaller, if determined with etalons of less than $4 \mathrm{~cm}$ length, than if greater retardations are employed. Inasmuch as we have employed etalons of $2.5 \mathrm{~cm}$ or less in the present investigation, the results should be on the same scale as the adopted secondary standards in neon.

\section{EXPERIMENTS}

The interferometer consisted of the same pair of crystal quartz plates, coated with evaporated aluminum, which were used in the recent determination of wave lengths of iron in the ultraviolet region. The coated surfaces of these plates were separated by etalons each made of three invar rods of $3,7.5,8,8.4,15,20$, or $25 \mathrm{~mm}$ length. All of these etalons were used only in the observations of neon.

A Littrow-type quartz spectrograph (Hilger E1) was employed for most of the exposures, although a few exposures were made in a Cornu prism spectrograph (Hilger E2). Two Zeiss quartz-fluorite objectives were available for projecting the interference pattern upon the slit of the spectrograph, one of $25 \mathrm{~cm}$, the other of $50-\mathrm{cm}$ focal length, the choice being determined by the length of etalon. The $25-\mathrm{cm}$ projector was used in a few instances with the 7.5- $\mathrm{mm}$ etalon and in all cases with the $3-\mathrm{mm}$ etalon. The interferometer was illuminated with parallel light by means of a quartz lens. Care was taken to line up the interferometer and all optical accessories coincident with the axis of the spectrograph. The interferometer was also placed at such a distance from the ring projector as to be focused upon the prism of the spectrograph.

All wave-length determinations here reported are relative to the krypton secondary standards in the wave-length interval between 4502 and 4274 A [1]. Krypton was chosen because of the superior sharpness of the standard lines and because the location of these lines at the lower wave-length end of the visible region simplifies comparisons with lines in the same region and in the nearby ultraviolet, and minimizes errors due to the necessity of focusing a spectrograph for widely separated regions. In making measurements in the krypton spectrum relative to krypton standards only one source is needed, affording the obvious advantage of identical conditions of illumination for all lines. The same advantage might be claimed for comparing neon ultraviolet lines with neon standards, but the intensity disparity is so great that it is practically impossible to record the first without overexposing the latter. Krypton standards seemed the obvious choice for the argon comparisons, because the blue and violet argon lines lie in the same region as the krypton standards, so that atmospheric and phase corrections are negligible over a considerable wavelength interval. It was also felt that inasmuch as previous determina- 
tions had been made relative to cadmium or neon, it was advantageous to make independent comparisons with krypton.

The krypton sources were Geissler tubes purchased from Robert Götze, in Leipzig. These tubes are listed in the maker's catalog as type $D$. They have a small capillary bore, about $1.5 \mathrm{~mm}$, cylindrical aluminum electrodes, and are designed for either end-on or side-on illumination. The pressures are not specified for the krypton-filled tubes, but in these experiments the discharge characteristics indicated $1 \mathrm{~mm}$ or less. The krypton tubes were always used in the side-on position.

Several different neon tubes were used, and part of these were of the same manufacture and type as the krypton tubes. Others were of similar design but of larger capillary bore, made by the Linde Air Products Co. Still another, filled with gas at a pressure of several millimeters, was used in a series of observations to see whether pressure displacements could be measured. No systematic variations were found in the results to indicate that wave lengths obtained from different tubes were not identical within the limits of accidental error.

Both Linde and Götze argon tubes were used. The exhaustion of our supply of "low" pressure Götze tubes early in the investigation proved something of a handicap, because the illumination from the Linde tubes was of low intensity. Götze tubes filled to a pressure of $20 \mathrm{~mm}$ of $\mathrm{Hg}$ did not prove satisfactory, because there was very noticeable line broadening and some evidence of pressure displacement. It is not felt that the present investigation warrants any conclusions regarding pressure effect, except that it is a negligible factor if the pressures within the sources are of the order of $1 \mathrm{~mm}$ of $\mathrm{Hg}$.

The pressure in a tube filled with a noble gas diminishes during operation due to the occlusion of gas by material sputtered from the electrodes. This is the usual cause of eventual tube failure. This lowering of pressure during use makes an accurate quantitative estimate of pressure in a sealed tube practically impossible. We have already referred to the work of Jackson [5] on the pressure effect of krypton. Further quantitative measurements are desirable in view of theoretical studies which are being made [9]. In any such investigation the sources should be connected to pressure gages, permitting simultaneous accurate determinations of both wave lengths and pressures.

Because of the difference in intensities of the various lines, a very large range in exposure times was necessary to record satisfactory patterns. These ranged from a few minutes for the strongest neon lines to 16 hours for the weakest krypton lines. Patterns of krypton and neon photographed with a $3-\mathrm{mm}$ etalon are reproduced in figure 2 . With this interference path, the fringes of close neon pairs at 3593 , 3418 , and 3370 A are fully separated.

In the work with neon or argon where two sources are required, simultaneous exposures were made in most instances. This procedure necessitates such a disposition of both sources that each illuminates the apparatus in a manner optically equivalent. The usual scheme 


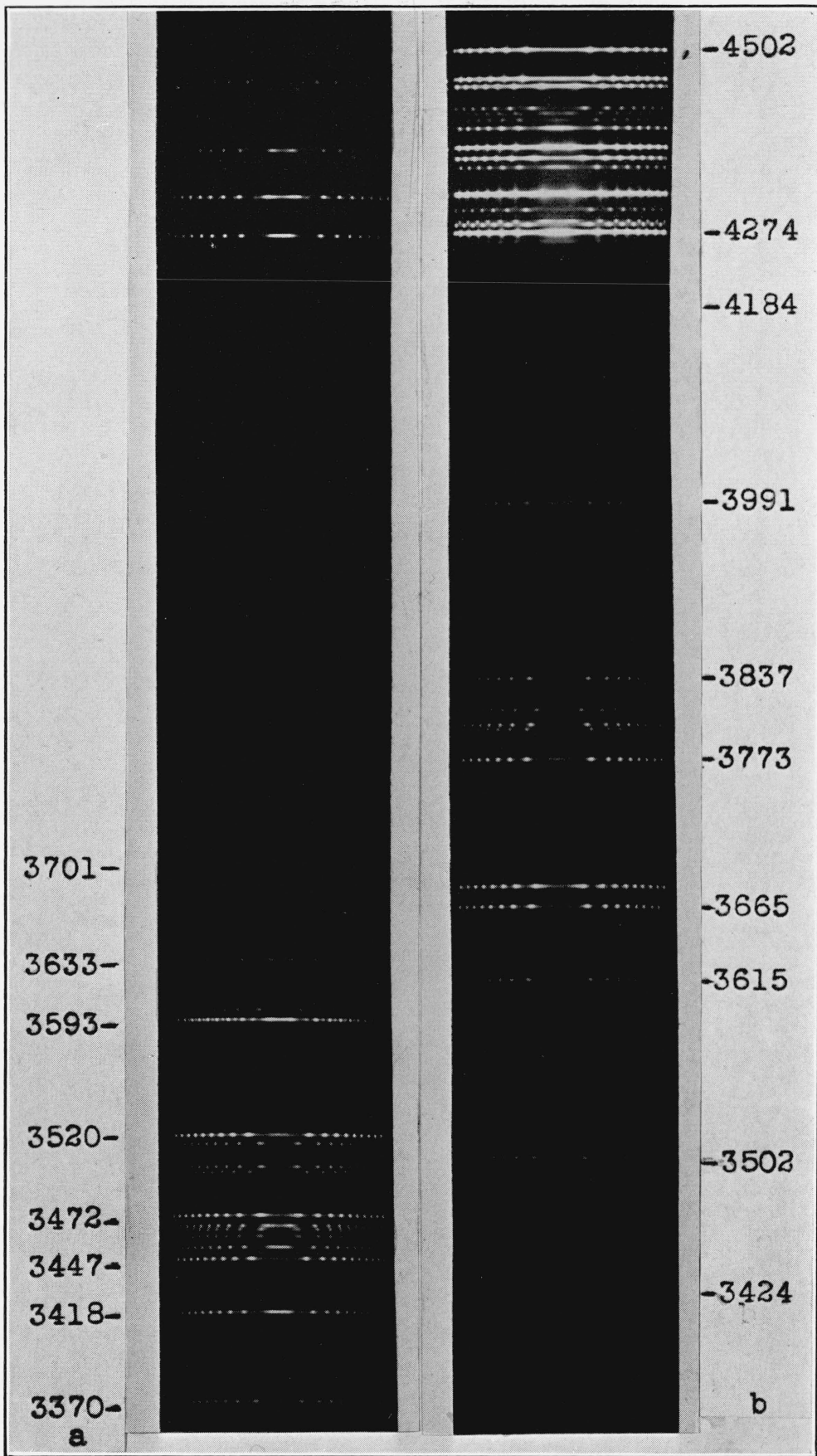

Figure 2.-Fabry-Perot interference patterns of (a) neon photographed simultaneously with krypton and (b) krypton (3-mm etalon). 
is to place an inclined transparent plane mirror (a quartz plate in these experiments) between the first source and condensing lens, and reflect light from the second source into the path of the direct beam by aid of this mirror. The choice of sources for the two positions will depend on the relative intensities of the lines to be compared. A second scheme, feasible only if one of the tubes is of large capillary bore, is to place this tube in the correct position for best illumination of the interferometer. Behind the source and in line with the other units in the setup is placed a concave mirror at a distance about equal to its radius of curvature and slightly inclined to the axis. The second source is placed at the conjugate focus of this mirror and its image is brought into coincidence with the first source. In the smaller number of instances where exposures were alternated, the alternations were made frequently and the total exposure time was short, so that on the average the atmospheric conditions during the exposure of each tube could be regarded as equivalent.

The procedure of measuring, reducing, correcting, and adjusting the observations to arrive at the final reported wave-length values was carried out in accordance with methods which have been described fully in other publications. The theory of the Fabry-Perot interferometer given originally by Fabry and Buisson [10] was discussed in some detail in an earlier paper by the author [8]. The interference patterns were measured with the micrometer designed for this purpose, which is illustrated in the recent publication on interference measurements in the iron spectrum [11]. This paper also gives the details of the method of reducing observations which is followed at present. As far as possible, the same over-all size of interference pattern was measured for both primary and secondary standards. This could be accomplished conveniently by measuring the diameters of five rings in the ultraviolet and four in the region of the krypton standards. The correct order numbers for the standard lines and the length of the interference path were obtained by the method illustrated for neon by Meggers [12].

The corrections for deviations of atmospheric density from standard conditions (dry air at $15^{\circ} \mathrm{C}$ and $760 \mathrm{~mm}$ of $\mathrm{Hg}$ ) derived from observations of the mean air temperature and barometric pressure for each exposure, were taken from tables prepared for this purpose by Meggers and Peters [13].

The corrections for dispersion of phase change at reflection were obtained by comparison of the data from 25- and 3-mm etalons, 20and 3-mm etalons, and 7.5- and 3-mm etalons [12]. These corrections were positive below $3950 \mathrm{~A}$ and increased in magnitude to a maximum near 3400 , amounting to about $0.001 \mathrm{~A}$ for the 7.5 etalon in this region. This behavior of the plates, a little surprising in view of the negative correction in the region between 3500 and $2000 \mathrm{~A}$ found when iron wave lengths were determined relative to neon, indicates that the correction curve has a minimum near $4000 \mathrm{~A}$ and a maximum near $3400 \mathrm{~A}$. 


\section{RESULTS}

The final results of the determinations of wave length in the first spectra of neon, argon, and krypton are presented in tables 1, 3, and 5. The values were arrived at by taking a weighted mean of the averages of the corrected values obtained with the various etalons. The weights were based on the number of observations and the length of interference path, except in cases of pairs of lines most clearly resolved by certain etalons, in which cases the weights were chosen arbitrarily. The total number of observations is reported with each wave length.

Construction of arrays of term combinations, as displayed in tables 2,4 , and 6 , shows that term differences are repeated to within oneor two-thousandths of a wave number in the great majority of cases. The retention of eight figures in the reported wave-length values is amply justified in all but a few cases. Calculation of the probable error of the weighted mean gave an average probable error of about 1 in the eighth place and gave a little under 3 for the neon wave length regarded as being least reliably determined. These probable errors are not reported because it is questioned if the variation in observed values, after all corrections are applied, conforms closely enough to the theory of accidental errors. For instance, it frequently happens that individual values obtained with the same etalon agree more closely than the averages from different etalons for the same line, indicating a dependence of apparent wave length upon order. Hyperfine structure or the presence of a nearby line, which may or may not be observed, can account for this, but the theory of errors is hardly applicable to such cases.

\section{NEON}

The adopted secondary standards of neon include most of the $1 s-2 p$ quantum transitions. This investigation is concerned with the next set of series members $1 s-3 p$. The visible blue and violet krypton, and the blue and violet argon lines originate in analogous transitions from corresponding levels in the respective atoms. The theory predicts 30 such transitions. One of these, $1 s_{3}-3 p_{7}$, has never been observed. Of the 29 remaining, 27 have been observed by interference methods in the present investigation. All of these are shown in table 1. A maximum of 40 exposures were recorded for some of the neon lines. This number, somewhat greater than required to arrive at satisfactory final values, was accumulated because the correction curve for dispersion of phase change at reflection showed a somewhat unexpected form in the region under investigation and an unusually large number of observations were needed to fix it precisely. Additional observations with critical lengths of interference path were also occasioned by the attempt to separate close pairs of lines. The 8.4-mm etalon was made available through the kindness of the staff of the Allegheny Observatory. Its length is very nearly one of the calculated separations required to give the optimum resolution of the close pairs of lines involving the $3 p_{2}$ and $3 p_{4}$ levels, which are only $0.88 \mathrm{~cm}^{-1}$ apart. 
TABLE 1.-Neon I interference measurements

\begin{tabular}{|c|c|c|c|}
\hline$\lambda_{a i r} \mathrm{~A}$ & $\begin{array}{l}\text { Number } \\
\text { of obser- } \\
\text { vations }\end{array}$ & $\nu_{g a e} \mathrm{~cm}^{-1}$ & Combination \\
\hline $\begin{array}{l}3754.2160 \\
3701.2250 \\
3685.7359 \\
3682.2428 \\
3633.6646\end{array}$ & $\begin{array}{l}22 \\
36 \\
36 \\
32 \\
38\end{array}$ & $\begin{array}{l}26629.180 \\
27010.424 \\
27123.931 \\
27149.660 \\
27512.613\end{array}$ & $\begin{array}{l}1 s_{2}-3 p_{10} \\
1 s_{2}-3 p_{8} \\
1 s_{2}-3 p_{7} \\
1 s_{2}-3 p_{6} \\
1 s_{2}-3 p_{3}\end{array}$ \\
\hline $\begin{array}{l}3609.1793 \\
3600.1693 \\
3593.6398 \\
3593.5259 \\
3520.4717\end{array}$ & $\begin{array}{l}19 \\
38 \\
32 \\
32 \\
40\end{array}$ & $\begin{array}{l}27699.259 \\
27768.579 \\
27819.031 \\
27819.913 \\
28397.194\end{array}$ & $\begin{array}{l}1 s_{3}-3 p_{10} \\
1 s_{2}-3 p_{5} \\
1 s_{2}-3 p_{2} \\
1 s_{2}-3 p_{4} \\
1 s_{2}-3 p_{1}\end{array}$ \\
\hline $\begin{array}{l}3515.1908 \\
3510.7214 \\
3501.2165 \\
3498.0644 \\
3472.5711\end{array}$ & $\begin{array}{l}38 \\
33 \\
39 \\
39 \\
40\end{array}$ & $\begin{array}{l}28439.854 \\
28476.059 \\
28553.362 \\
28579.091 \\
28788.893\end{array}$ & $\begin{array}{l}1 s_{4}-3 p_{8} \\
1 s_{5}-3 p^{10} \\
1 s_{4}-3 p_{7} \\
1 s_{4}-3 p_{6} \\
1 s_{5}-3 p_{9}\end{array}$ \\
\hline $\begin{array}{l}3466.5786 \\
3464.3389 \\
3460.5245 \\
3454.1952 \\
3450.7653\end{array}$ & $\begin{array}{l}40 \\
38 \\
38 \\
40 \\
37\end{array}$ & $\begin{array}{l}28838.658 \\
28857.302 \\
28889.108 \\
28942.041 \\
28970.808\end{array}$ & $\begin{array}{l}1 s_{3}-3 p_{5} \\
1 s_{5}-3 p_{8} \\
1 s_{3}-3 p_{2} \\
1 s_{4}-3 p_{3} \\
1 s_{5}-3 p_{7}\end{array}$ \\
\hline $\begin{array}{l}3447.7029 \\
3423.9127 \\
3418.0066 \\
3417.9036 \\
3375.6498\end{array}$ & $\begin{array}{r}40 \\
24 \\
25 \\
40 \\
6\end{array}$ & $\begin{array}{l}28996.541 \\
29198.009 \\
29248.461 \\
29249.342 \\
29615.450\end{array}$ & $\begin{array}{l}1 s_{5}-3 p_{6} \\
1 s_{4}-3 p_{5} \\
1 s_{4}-3 p_{2} \\
1 s_{4}-3 p_{4} \\
1 s_{5}-3 p_{6}\end{array}$ \\
\hline $\begin{array}{l}3369.9081 \\
3369.8086\end{array}$ & $\begin{array}{l}38 \\
24\end{array}$ & $\begin{array}{l}29665909 \\
29666.784\end{array}$ & $\begin{array}{l}1 s_{5}-3 p_{2} \\
1 s_{5}-3 p_{4}\end{array}$ \\
\hline
\end{tabular}

The complete array of term combinations, $1 s-2 p$ and $1 s-3 p$, have been assembled in table 2. Except for $29615.450 \mathrm{~cm}^{-1}$, which is the faintest of the group, and $29666.784 \mathrm{~cm}^{-1}$ which is difficult to measure on account of proximity to $29665.909 \mathrm{~cm}^{-1}$, the relative accuracy of the $1 s-3 p$ group is fully equal to that shown in the $1 s-2 p$ array, which includes all the adopted neon secondary standards. The remaining eight-figure wave numbers of visible and infrared lines appearing in table 2 are averages of the determinations relative to cadmium and neon reported by Meggers and Humphreys in 1934 [2]. A few sevenfigure values required to complete the table are quoted from Paschen [4]. Only interferometer determinations are considered in estimating term values or relative accuracy. The term values shown in table 2 are revised to give the best agreement with all the experimental material. The difference, calculated minus observed wave number, is recorded beneath the last figure of each wave number value, considered in adopting term values. The average deviation of calculated term combinations from the observed wave numbers is 1 part in $20,000,000$. Calculated values of wave numbers of lines too faint to be observed by interferometers are shown in parenthesis beneath values resulting from measurements of grating spectrograms. 
TABLE 2.-Neon 1 array of $1 s-2 p$ and $1 s-30$ combinations

\begin{tabular}{|c|c|c|c|c|c|c|c|c|c|}
\hline$\underset{\substack{\text { Term } \\
\text { symbol }}}{\downarrow}$ & $\begin{array}{l}j \\
\downarrow\end{array}$ & $\begin{array}{c}\text { Term } \\
\text { value } \\
\downarrow\end{array}$ & $\begin{array}{c}1 s_{2} \\
j=1 \\
38040.730\end{array}$ & $\begin{array}{c}\text { Diff. } \\
1070.079\end{array}$ & $\begin{array}{c}1 s_{3} \\
0 \\
39110.809\end{array}$ & $\begin{array}{c}\text { Diff. } \\
359.353\end{array}$ & $\begin{array}{c}18_{4} \\
1 \\
39470.163\end{array}$ & $\begin{array}{c}\text { Diff. } \\
417.448\end{array}$ & $\begin{array}{c}18_{8} \\
39887.610\end{array}$ \\
\hline $3 p_{1}$ & 0 & 9643. 536 & 28397.194 & & * & & 29826. & & * \\
\hline $3 p_{2}$ & 1 & 10221.701 & 27819. 031 & 1070.077 & 28889.108 & 359.353 & 29248 & 417.448 & 29665.909 \\
\hline $3 p_{3}$ & 0 & 10528. 119 & 27512.613 & & * & & 28942. 041 & & \\
\hline $3 p_{4}$ & 2 & 10220.819 & 27819.913 & & - & -... & 29249. 342 & 417.442 & 29666. 784 \\
\hline $3 p_{5}$ & 1 & 10272.152 & 27768. 579 & 1070.079 & 28838.658 & 359.351 & 29198.009 & 417.441 & 29615. 450 \\
\hline $3 p_{6}$ & 2 & 10891.070 & $27149 . \overline{660}$ & & & & 28579. 091 & 417.450 & $\begin{array}{r}+8 \\
28996.541\end{array}$ \\
\hline $3 p_{7}$ & 1 & 10916.800 & 27123. 031 & & & & 28553. 362 & 417.446 & 28970.808 \\
\hline $3 p_{8}$ & 2 & 11030.307 & 27010.424 & & * & & 28439. $\begin{array}{l} \pm 0 \\
854\end{array}$ & 417.448 & 28857.302 \\
\hline $\begin{array}{l}3 p_{9} \\
3 p_{10}\end{array}$ & $\begin{array}{l}3 \\
1\end{array}$ & $\begin{array}{l}11098.717 \\
11411.550\end{array}$ & 26629.180 & 1070.079 & $\stackrel{*}{*} 27699.259$ & * & $\begin{array}{r}*+1 \\
28058.69\end{array}$ & & $\begin{array}{r}+1 \\
28788.893 \\
28476.059\end{array}$ \\
\hline $2 p_{1}$ & 0 & 20958. 703 & $\begin{array}{r} \pm 0 \\
17082.027\end{array}$ & & & & $\begin{array}{r}(8.612) \\
18511.459\end{array}$ & & \\
\hline $2 p_{2}$ & 1 & 22890.987 & 15149.743 & 1070.078 & 16219.821 & 359.354 & 16579. $\stackrel{ \pm 0}{175}$ & 417.448 & 16996.623 \\
\hline $\begin{array}{l}2 p_{3} \\
2 p_{4}\end{array}$ & ${ }_{2}^{0}$ & $\begin{array}{l}23012.009 \\
23070.932\end{array}$ & $\begin{array}{l}15028.71 \\
14969.798\end{array}$ & & & & $\begin{array}{l} \pm 0 \\
\text { 16458. } 153 \\
16399.231\end{array}$ & 417.447 & $\begin{array}{r}{ }^{*} \pm 0 \\
16816 .\end{array}$ \\
\hline $2 p_{5}$ & 1 & 23157.328 & 14883. 402 & 1070.079 & 15953.481 & 359.350 & 16312.831 & 417.451 & $16730 . \begin{array}{l} \pm=0 \\
282\end{array}$ \\
\hline $2 p_{6}$ & 2 & 23613. 579 & 14427. $\begin{array}{l} \pm 0 \\
150\end{array}$ & & & & $\begin{array}{r}+3 \\
15856.582\end{array}$ & 417.450 & $\begin{array}{r}16274.032 \\
\pm 0\end{array}$ \\
\hline $2 p_{7}$ & 1 & 23807.849 & 14232.880 & 1070.079 & 15302.959 & 359.355 & 15662. $\begin{array}{r}+1 \\
314\end{array}$ & 417.447 & 16079.761 \\
\hline $2 p_{8}$ & 2 & 24105.219 & $\begin{array}{r}+1 \\
13935.509\end{array}$ & & & & $15364.9^{-1}$ & 417.448 & 15782. $\begin{array}{c} \pm 0 \\
391\end{array}$ \\
\hline $\begin{array}{l}2 p_{0} \\
2 p_{10}\end{array}$ & $\begin{array}{l}3 \\
1\end{array}$ & $\begin{array}{l}24272.400 \\
25671.654\end{array}$ & $\begin{array}{r}* \\
12369.076 \\
\pm 0\end{array}$ & 1070.079 & $\begin{array}{r}* \\
13439.155 \\
\pm 0\end{array}$ & 359.353 & $\begin{array}{r} \pm 0 \\
13798.508 \\
\pm 0\end{array}$ & 417.450 & $\begin{array}{r}15615.210 \\
14215.958 \\
-2\end{array}$ \\
\hline
\end{tabular}

\section{ARGON}

The suitability of argon lines as standards, on account of extreme homogeneity and freedom from structure, was recognized at the 1935 meeting of the IAU. The repetition and extension of measurements were recommended. The results given in table 3 include determinations relative to krypton of 40 lines over the range from 4702 to $3319 \mathrm{~A}$. Etalons of 15,20 , and $25 \mathrm{~mm}$ length were used in the comparisons. The sources used did not give very intense spectra, so that a number of ultraviolet lines remain, which could be observed by interference methods if sufficiently bright sources were employed. The earlier measurements of Meggers and Humphreys [2] and of Meggers [16] are included in table 3 for comparison insofar as they are within the wave-length range covered by this investigation. The agreement with Meggers' seven-figure values, published in 1921, is somewhat closer than with the 1934 results of Meggers and Humphreys. The latter are systematically lower, the difference being a little over $0.001 \mathrm{~A}$ for most lines. While we are certain that the relative accuracy of the 1934 values is at least as good as that of the results here reported, it still seems most probable that the systematic error is in the measurements of 1934. 
TABLE 3.-Argon I interference measurements

\begin{tabular}{|c|c|c|c|c|c|c|}
\hline $\begin{array}{c}\lambda_{\text {air }}, \mathrm{Kr} \\
\text { standard }\end{array}$ & $\begin{array}{l}\text { Number } \\
\text { of obser- } \\
\text { vations }\end{array}$ & $\begin{array}{c}\text { Meggers } \\
\text { and Hum- } \\
\text { phreys [2] } \\
\text { Cd stand- } \\
\text { ard }\end{array}$ & $\begin{array}{c}\text { Meggers } \\
\text { and Hum- } \\
\text { phreys [2] } \\
\text { Ne stand- } \\
\text { ard }\end{array}$ & $\begin{array}{l}\text { Meggers } \\
{[16] \mathrm{Cd}} \\
\text { standard }\end{array}$ & $\begin{array}{c}\nu_{\text {vac }} \mathrm{cm}^{-1} \\
\mathrm{Kr} \text { standard }\end{array}$ & Combination \\
\hline A & & A & A & A & & \\
\hline $\begin{array}{l}4702.3164 \\
4628.4410 \\
4596.0970 \\
4522.3238 \\
4510.7333\end{array}$ & $\begin{array}{l}11 \\
10 \\
11 \\
11 \\
13\end{array}$ & 7324 & $\begin{array}{l}3151 \\
4398 \\
0964 \\
3216 \\
7322\end{array}$ & $\begin{array}{l}317 \\
445 \\
096 \\
325 \\
733\end{array}$ & $\begin{array}{l}21260.184 \\
21599.518 \\
21751.516 \\
22106.347 \\
22163.149\end{array}$ & $\begin{array}{l}1 s_{2}-3 p_{10} \\
1 s_{2}-3 p_{8} \\
1 s_{2}-3 p_{7} \\
1 s_{3}-3 p_{10} \\
1 s_{2}-3 p_{5}\end{array}$ \\
\hline $\begin{array}{l}\text { 4345. } 1682 \\
4335.3380 \\
4333.5612 \\
4300.1011 \\
4272.1690\end{array}$ & $\begin{array}{l}13 \\
13 \\
13 \\
13 \\
13\end{array}$ & $\begin{array}{l}3363 \\
5601 \\
1000 \\
1678\end{array}$ & $\begin{array}{l}1666 \\
3370 \\
5595 \\
0995 \\
1680\end{array}$ & $\begin{array}{l}168 \\
561 \\
101 \\
169\end{array}$ & $\begin{array}{l}23007.623 \\
23059.791 \\
23069.245 \\
23248.750 \\
23400.751\end{array}$ & $\begin{array}{l}1 s_{2}-3 p_{4} \\
1 s_{2}-3 p_{2} \\
1 s_{2}-3 p_{3} \\
1 s_{4}-3 p_{8} \\
1 s_{4}-3 p_{7}\end{array}$ \\
\hline $\begin{array}{l}4266.2867 \\
4259.3618 \\
4251.1852 \\
4200.6751 \\
4198.3170\end{array}$ & $\begin{array}{l}13 \\
13 \\
13 \\
13 \\
13\end{array}$ & $\begin{array}{l}2855 \\
3607 \\
\\
6738 \\
3160\end{array}$ & $\begin{array}{l}2853 \\
3603 \\
1842 \\
674 \\
316\end{array}$ & $\begin{array}{l}286 \\
362 \\
184 \\
676 \\
316\end{array}$ & $\begin{array}{l}23433.014 \\
23471.111 \\
23516.254 \\
23799.015 \\
23812.383\end{array}$ & $\begin{array}{l}1 s_{4}-3 p_{0} \\
1 s_{2}-3 p_{1} \\
1 s_{5}-3 p_{10} \\
1 s_{5}-3 p_{0} \\
1 s_{4}-3 p_{5}\end{array}$ \\
\hline $\begin{array}{l}\text { 4191. } 0296 \\
4190.7127 \\
4181.8838 \\
4164.1800 \\
4158.5906\end{array}$ & $\begin{array}{r}7 \\
7 \\
13 \\
13 \\
13\end{array}$ & $\begin{array}{l}0270 \\
7098 \\
8825 \\
1789 \\
5895\end{array}$ & $\begin{array}{l}8826 \\
1788 \\
5896\end{array}$ & $\begin{array}{l}027 \\
714 \\
884 \\
180 \\
591\end{array}$ & $\begin{array}{l}23853.787 \\
23855.591 \\
23905.955 \\
24007.587 \\
24039.854\end{array}$ & $\begin{array}{l}1 s_{3}-3 p_{4} \\
1 s_{5}-3 p_{8} \\
1 s_{3}-3 p_{2} \\
1 s_{5}-3 p_{7} \\
1 s_{5}-3 p_{6}\end{array}$ \\
\hline $\begin{array}{l}4054.5254 \\
4045.9658 \\
4044.4182 \\
3948.9788 \\
3947.5043\end{array}$ & $\begin{array}{r}7 \\
7 \\
13 \\
13 \\
9\end{array}$ & & $\begin{array}{l}5250 \\
4173 \\
977\end{array}$ & $\begin{array}{l}419 \\
980\end{array}$ & $\begin{array}{l}24656.860 \\
24709.022 \\
24718.477 \\
25315.863 \\
25325.319\end{array}$ & $\begin{array}{l}1 s_{4}-3 p_{4} \\
1 s_{4}-3 p_{2} \\
1 s_{4}-3 p_{3} \\
1 s_{5}-3 p_{2} \\
1 s_{5}-3 p_{3}\end{array}$ \\
\hline $\begin{array}{l}3894.6602 \\
3834.6785 \\
3781.3609 \\
3770.3688 \\
3690.8957\end{array}$ & $\begin{array}{r}6 \\
12 \\
2 \\
2 \\
7\end{array}$ & & & & $\begin{array}{l}25668.934 \\
26070.436 \\
26438.023 \\
26515.098 \\
27086.013\end{array}$ & $\begin{array}{l}1 s_{2}-4 p_{10} \\
1 s_{2}-4 p_{3} \\
1 s_{4}-4 \mathrm{X} \\
1 s_{3}-4 p_{10} \\
1 s_{8}-4 \mathrm{Y}\end{array}$ \\
\hline $\begin{array}{l}3649.8324 \\
3 € 34.4605 \\
3632.6837 \\
3606.5224 \\
3567.6565\end{array}$ & $\begin{array}{r}9 \\
8 \\
8 \\
12 \\
13\end{array}$ & & & & $\begin{array}{l}27390.742 \\
27506.588 \\
27520.042 \\
27719.664 \\
28021.631\end{array}$ & $\begin{array}{l}1 s_{2}-4 p_{1} \\
1 s_{4}-4 p_{7} \\
1 s_{4}-4 p_{6} \\
1 s_{4}-4 p_{5} \\
1 s_{8}-4 p_{0}\end{array}$ \\
\hline $\begin{array}{l}\text { 3554. } 3061 \\
3461.0780 \\
3393.7517 \\
3373.481 \\
3319.3446\end{array}$ & $\begin{array}{r}13 \\
5 \\
5 \\
2 \\
3\end{array}$ & - & & & $\begin{array}{l}28126.882 \\
28884.489 \\
29457.490 \\
29634.49 \\
30117.793\end{array}$ & $\begin{array}{l}1 s_{5}-4 p_{6} \\
1 s_{4}-4 p_{3} \\
1 s_{5}-5 p_{4} \\
1 s_{4}-5 p_{5} \\
1 s_{5}-5 p_{6}\end{array}$ \\
\hline
\end{tabular}

The argon lines lie in the same wave-length region as the blue and violet krypton standards, eliminating the possibility of an error in the new measurements due to the spectrograph not being focused exactly alike for both sources, or an error due to incorrect estimate of the correction for dispersion of phase change at reflection. An error of the kind first mentioned is possible when a prism spectrograph is being used and comparisons are being made, relative to standards in the red region, of lines in the blue or ultraviolet. The reason is that the patterns due to the standard lines appear at one end of the plate where the focusing is less satisfactory than at the center. The plate curvature in such a spectrograph gives only a fair approximation to the true focal surface. The difficulty is somewhat increased by the fact that the spectrograph is slightly astigmatic, and it is necessary to choose the most satisfactory compromise between the best adjustments for vertical and horizontal images, this compromise to be the same, if possible, for all spectral regions. 
TABLE 4.-Argon I array of $1 s-n p$ combinations

\begin{tabular}{|c|c|c|c|c|c|c|c|c|c|}
\hline $\begin{array}{c}\text { Term } \\
\text { symbol } \\
\downarrow\end{array}$ & $\begin{array}{l}j \\
\downarrow\end{array}$ & $\begin{array}{c}\text { Term } \\
\text { value } \\
\downarrow\end{array}$ & $\begin{array}{c}1 s 2 \\
j=1 \\
31711.630\end{array}$ & $\begin{array}{l}\text { Diff. } \\
846.163\end{array}$ & $\begin{array}{c}1 s_{3} \\
0 \\
32557.793\end{array}$ & $\begin{array}{l}\text { Diff. } \\
803.068\end{array}$ & $\begin{array}{c}18_{4} \\
1 \\
33360.861\end{array}$ & $\begin{array}{c}\text { Diff. } \\
606.839\end{array}$ & $\begin{array}{c}18 \mathrm{~s} \\
2 \\
33967.700\end{array}$ \\
\hline $4 p_{1}$ & 0 & 4320.888 & 27390.742 & & * & & 290 & & * \\
\hline $4 p_{3}$ & 2 & 4476.372 & 27235. 47 & & * & & 28884.489 & & 29491. 39 \\
\hline $4 p_{5}$ & 0 & 5641.196 & 26070.436 & & * & & 27719.664 & & $(1.328)$ \\
\hline $4 p_{6}$ & 2 & 5840.818 & $25870 . \overline{87}$ & & * & & $\begin{array}{r}+1 \\
27520.042\end{array}$ & 606.840 & 28126.882 \\
\hline $4 p_{7}$ & 1 & 5854.273 & $\begin{array}{r}(0.812) \\
25857.35\end{array}$ & & 26703.55 & & 27506. $\begin{array}{r}+1 \\
588\end{array}$ & & 28113. 720 \\
\hline $\begin{array}{l}4 p_{9} \\
4 p_{10}\end{array}$ & $\begin{array}{l}3 \\
1\end{array}$ & $\begin{array}{l}5946.069 \\
6042.696\end{array}$ & $\begin{array}{r}* .35 \%) \\
25668.934\end{array}$ & 846.164 & $\begin{array}{r}(3.520) \\
* 15.098 \\
26515.098\end{array}$ & & 27318. 38 & & $\begin{array}{r}\text { (3. 427) } \\
28021.631\end{array}$ \\
\hline $3 p_{1}$ & 0 & 8240.519 & 23471. $\begin{array}{r} \pm 0 \\
111\end{array}$ & & $*^{-1}$ & & $\begin{array}{c}(8.165) \\
25120.41 \\
(0.342)\end{array}$ & & * \\
\hline $3 p_{2}$ & 1 & 8651.838 & $\begin{array}{r}23059.791 \\
+1\end{array}$ & 846. 164 & $\begin{array}{r}23905.955 \\
\pm 0\end{array}$ & 803.067 & $\begin{array}{r}24709.022 \\
+1\end{array}$ & 606.841 & 25315. 863 \\
\hline $3 p_{3}$ & 2 & 8642.383 & 23069. 245 & &. \pm 0 & & 24718. 477 & 606.842 & 25325. 319 \\
\hline $3 p_{4}$ & 1 & 8704.006 & $\begin{array}{r}23007.623 \\
+1\end{array}$ & 846.164 & $\begin{array}{r}23853.787 \\
\pm 0\end{array}$ & 803. 073 & $\begin{array}{r}24656.860 \\
-5\end{array}$ & & \\
\hline $3 p_{5}$ & 0 & 9548.480 & 22163. 149 & & $*$ & & 23812. 383 & & * \\
\hline $3 p_{6}$ & 2 & 9927.846 & $\begin{array}{l}21783.78 \\
(3.784)\end{array}$ & & * & & 23433. 014 & 606.840 & 24039.854 \\
\hline $3 p_{7}$ & 1 & 9960.113 & $\begin{array}{l}21751.516 \\
+1\end{array}$ & & $\begin{array}{l}22597.75 \\
(7.680)\end{array}$ & & 23400.751 & 606.836 & 24007. 587 \\
\hline $3 p_{8}$ & 2 & 10112. 111 & 21599. 518 & & $(7.680)$ & & 23248.750 & 606.841 & 23855. $\begin{array}{l} \pm 0 \\
591\end{array}$ \\
\hline $\begin{array}{l}3 p_{9} \\
3 p_{10}\end{array}$ & $\begin{array}{l}3 \\
1\end{array}$ & $\begin{array}{l}10168.685 \\
10451.446\end{array}$ & 21260.184 & 846.163 & $\stackrel{*}{*} 22106.347$ & & $\begin{array}{c}* \pm 0 \\
22909.44 \\
(9.415)\end{array}$ & & $\begin{array}{r}23799.015 \\
23516.254\end{array}$ \\
\hline $2 p_{1}$ & 0 & 18388. 832 & $\begin{array}{l}13322.70 \\
-799 \\
-1\end{array}$ & & & & $\begin{array}{r}\text { 1972. } 027) \\
+2\end{array}$ & & \\
\hline $2 p_{8}$ & 1 & 19615. 037 & $\begin{array}{r}12096.593 \\
+0\end{array}$ & 846.163 & $\begin{array}{r}12942.756 \\
\pm 0\end{array}$ & 803.068 & 13745.824 & 606.839 & 14352. 663 \\
\hline $2 p_{3}$ & 2 & 19821.753 & 11889.877 & & & & 13539. 108 & 606.839 & 14145.947 \\
\hline $2 p_{4}$ & 1 & 19979.745 & 11731.885 & 846.163 & 12578.048 & & $\begin{array}{l}13381.08 \\
(1.116)\end{array}$ & & 13987. 955 \\
\hline $\begin{array}{l}2 p_{5} \\
2 p_{6}\end{array}$ & $\begin{array}{l}0 \\
2\end{array}$ & $\begin{array}{l}20057.181 \\
20873.903\end{array}$ & $\begin{array}{r}10 \\
10837.727 \\
+0\end{array}$ & & * & & $\begin{array}{l}1330.680 \\
12486.959\end{array}$ & 606.838 & $\begin{array}{r}*^{ \pm 0} \\
13093.797\end{array}$ \\
\hline $2 p_{7}$ & 1 & 21024. 195 & 10687. $\begin{array}{l}=0 \\
+0\end{array}$ & 846.163 & 11533.598 & 803.068 & $\begin{array}{r}12336.666 \\
+0\end{array}$ & 606.839 & 12943. $\begin{array}{r} \pm 0 \\
505\end{array}$ \\
\hline $2 p_{8}$ & 2 & 21494.185 & 10217. 445 & & \pm 0 & & 11866.676 & 606. 838 & 12473. 514 \\
\hline $\begin{array}{l}2 p_{9} \\
2 p_{10}\end{array}$ & $\begin{array}{l}3 \\
1\end{array}$ & $\begin{array}{l}21648.696 \\
23009.356\end{array}$ & $\begin{array}{c}*{ }^{*} \\
8702.31 \\
(2.274)\end{array}$ & & $\begin{array}{r}* \\
9548.437 \\
\pm 0\end{array}$ & 803. 068 & $\begin{array}{r}* \pm 0 \\
10351.505 \\
\pm 0\end{array}$ & 606.838 & $\begin{array}{r}12319.004 \\
10958.343 \\
+1\end{array}$ \\
\hline
\end{tabular}

The array of argon term combinations shown in table 4 follows the same plan as the corresponding array for neon with the addition of a few $1 s-4 p$ transitions for which wave numbers determined by interference measurements are available. All eight figures wave numbers in the $1 s-3 p$ and $1 s-4 p$ arrays are from the results of this investigation. The $1 s-2 p$ array is assembled from the interference measurements by Meggers and Humphreys [2]. The values used are the averages of the determinations relative to cadmium and those relative to neon. The few seven-place wave numbers required to complete the array are Meissner's [14]. The term values are adjusted from the interference determinations. The relative accuracy of the measurements, which can be judged from the agreement of the observed with calculated wave numbers, and the constancy of repeated term differences is of the same order as that shown by the neon array. 


\section{KRYPTON}

The possibility of making interference measurements of ultraviolet krypton lines became apparent when a number of them appeared among the $1 s-3 p$ neon lines which were being determined relative to krypton. By rather long exposures, it was possible to obtain measurable patterns for 30 ultraviolet lines. Measurements were made on several fourth members of $1 s-\mathrm{n} p$-type series, permitting the evaluation of all but one of the $5 p$ terms by interference measurements. Several combinations of $f$ type terms were observed. Two lines, 3837.8162 and $3503.8981 \mathrm{~A}$, were shown by more precise measurements to be first and second members of a new series, $1 s_{5}-n \mathrm{~T}$, and not $1 s_{5}-n \mathrm{Y}$, as at present classified [15]. The T series of terms have $j$-value, 3 , and combine only with $s_{5}$. A new line, $3837.7028 \mathrm{~A}$, was revealed as a close companion to $3837.8162 \mathrm{~A}$ and is properly classified as $1 s_{5}-4 \mathrm{Y}$. Interference measurements were made of seven lines not included in the list of secondary standards but lying in the same region. Etalons of $3,7.5,20$, and $25 \mathrm{~mm}$ length were used in the wave-length comparisons, the results of which are assembled in table 5 , together with the results of previous measurements in the same wave-length interval.

TABLE 5.-Krypton I interference measurements

\begin{tabular}{|c|c|c|c|c|c|c|}
\hline $\begin{array}{l}\lambda_{\text {air }} \\
\text { Kr stand- } \\
\quad \text { ard }\end{array}$ & $\begin{array}{l}\text { Number } \\
\text { of obser- } \\
\text { vations }\end{array}$ & $\begin{array}{l}\text { Jackson [5] } \\
\text { Cd stand- } \\
\quad \text { ard }\end{array}$ & $\begin{array}{l}\text { Hum- } \\
\text { phreys [8] } \\
\text { Ne stand- } \\
\text { ard }\end{array}$ & $\begin{array}{l}\text { Meggers } \\
\text { and } \\
\text { Hum- } \\
\text { phreys [2] } \\
\text { Ne stand- } \\
\text { ard }\end{array}$ & $\begin{array}{l}\nu_{\mathrm{rac}}^{\mathrm{om}^{\mathrm{Om}-1}} \\
\mathrm{Kr} \text { stand- } \\
\text { ard }\end{array}$ & Combination \\
\hline A & & A & A & A & & \\
\hline $\begin{array}{l}4812.6367 \\
4550.2985 \\
4425.1908 \\
4418.7626 \\
4416.8838\end{array}$ & $\begin{array}{l}4 \\
5 \\
8 \\
8 \\
5\end{array}$ & $\begin{array}{l}2985 \\
1906 \\
764\end{array}$ & $\begin{array}{l}607 \\
298 \\
1909 \\
769\end{array}$ & 190 & $\begin{array}{l}20772.843 \\
21970.441 \\
22591.573 \\
22624.437 \\
22634.061\end{array}$ & $\begin{array}{l}1 s_{3}-4 \mathrm{X} \\
1 s_{4}-3 p_{10} \\
1 s_{2}-3 p_{4} \\
1 s_{2}-5 \mathrm{Z} \\
1 s_{2}-5 \mathrm{X}\end{array}$ \\
\hline $\begin{array}{l}4410.3685 \\
4302.4455 \\
4263.2881 \\
4184.4726 \\
3991.2581\end{array}$ & $\begin{array}{r}8 \\
3 \\
4 \\
7 \\
10\end{array}$ & 3687 & 369 & & $\begin{array}{l}22627.498 \\
23236.081 \\
23449.496 \\
23891.164 \\
25047.699\end{array}$ & $\begin{array}{l}1 s_{2}-3 p_{3} \\
1 s_{2}-5 p_{10} \\
1 s_{2}-5 p_{5} \\
1 s_{3}-5 p_{10} \\
1 s_{4}-4 \mathrm{X}\end{array}$ \\
\hline $\begin{array}{l}3991.0797 \\
3982.1699 \\
3815.9778 \\
3837.8162 \\
3837.7028\end{array}$ & $\begin{array}{r}11 \\
5 \\
9 \\
10 \\
2\end{array}$ & 8162 & & & $\begin{array}{l}25048.818 \\
25104.862 \\
25993.845 \\
26049.122 \\
26049.892\end{array}$ & $\begin{array}{l}1 s_{s}-4 Z \\
1 s_{4}-4 \mathrm{Y} \\
1 s_{s}-4 \mathrm{Z} \\
1 s_{s}-4 \mathrm{~T} \\
1 s_{5}-4 \mathrm{Y}\end{array}$ \\
\hline $\begin{array}{l}3812.2155 \\
3800.5437 \\
3796.8839 \\
3773.4241 \\
3698.0452\end{array}$ & $\begin{array}{l}11 \\
11 \\
11 \\
15 \\
17\end{array}$ & $\begin{array}{l}2159 \\
5440 \\
8844 \\
4247 \\
047\end{array}$ & & & $\begin{array}{l}26224.049 \\
26304.584 \\
26329.938 \\
26493.630 \\
27033.649\end{array}$ & $\begin{array}{l}1 s_{4}-4 p_{8} \\
1 s_{4}-4 p_{7} \\
1 s_{4}-4 p_{6} \\
1 s_{4}-4 p_{6} \\
1 s_{5}-4 p_{10}\end{array}$ \\
\hline $\begin{array}{l}3679.6111 \\
3679.5609 \\
3668.7363 \\
3665.3259 \\
3632.4896\end{array}$ & $\begin{array}{r}9 \\
22 \\
10 \\
22 \\
5\end{array}$ & $\begin{array}{l}7374 \\
3263\end{array}$ & & & $\begin{array}{l}27169.078 \\
27169.448 \\
27249.609 \\
27274.963 \\
27521.512\end{array}$ & $\begin{array}{l}1 s_{5}-4 p_{8} \\
1 s_{5}-4 p_{6} \\
1 s_{5}-4 p_{7} \\
1 s_{5}-4 p_{6} \\
1 s_{4}-3 p_{4}\end{array}$ \\
\hline $\begin{array}{l}3628.1570 \\
3615.4755 \\
3540.9538 \\
3539.5416 \\
3522.6747\end{array}$ & $\begin{array}{r}9 \\
11 \\
6 \\
6 \\
10\end{array}$ & $\begin{array}{l}1571 \\
4749\end{array}$ & & & $\begin{array}{l}27554.376 \\
27651.022 \\
28232.940 \\
28244.204 \\
28379.436\end{array}$ & $\begin{array}{l}1 s_{4}-5 Z \\
1 s_{4}-3 p_{2} \\
1 s_{4}-5 p_{7} \\
1 s_{4}-5 p_{6} \\
1 s_{4}-5 p_{5}\end{array}$ \\
\hline $\begin{array}{l}3511.8963 \\
3503.8981 \\
3502.5537 \\
3495.9900 \\
3434.1423\end{array}$ & $\begin{array}{r}6 \\
7 \\
11 \\
7 \\
5\end{array}$ & 9897 & & & $\begin{array}{l}28466.533 \\
28531.510 \\
28542.461 \\
28596.049 \\
29111.037\end{array}$ & $\begin{array}{l}1 s_{5}-3 p_{4} \\
185-5 \mathrm{~T} \\
18_{5}-3 p_{3} \\
185-3 p_{2} \\
18_{5}-5 p_{10}\end{array}$ \\
\hline $\begin{array}{l}3431.7217 \\
3424.9433\end{array}$ & $\begin{array}{l}10 \\
10\end{array}$ & $\begin{array}{l}7511 \\
9720\end{array}$ & & & $\begin{array}{l}29131.571 \\
29189.224\end{array}$ & $\begin{array}{l}1 s_{5}-5 p_{9} \\
1 s_{5}-5 p_{6}\end{array}$ \\
\hline
\end{tabular}


Jackson's [5] observations in the ultraviolet were made using a krypton tube filled to 4 -mm pressure, whereas ours were with pressures of $1 \mathrm{~mm}$ or less. The small but systematic difference between the two sets of values for the $1 s-4 p$ transitions is in essential agreement with Jackson's estimated pressure shifts. No attempt is made to explain the disagreement of Jackson's wave lengths of the lines 3431.7217 and 3424.9433 A with ours. Only the second value can be checked from the term array, but our value of the wave number $29189.224 \mathrm{~cm}^{-1}$ gives a fair fit, whereas Jackson's is outside the range of accidental error. Previous National Bureau of Standards' measurements of the visible lines included in the data were all from relatively faint patterns. The standards, and consequently the fainter lines, were not so heavily exposed as is necessary when making comparisons with ultraviolet lines. The agreement is, therefore, considered satisfactory. The disagreement of the 1930 [8] value for 4812 A was owing to an incorrect choice of order in the single available determination. A recheck of the original determination shows that it should have given $4812.636 \mathrm{~A}$.

Construction of the array of $1 s-n p$ term combinations in krypton, leads to a somewhat more extensive table than is the case with neon or argon, if all wave numbers determined by interference measurements are included. This is attributable to the appearance of higher series members in the more accessible part of the ultraviolet region. Such an array is shown in table 6 . The wave numbers there assembled include all results of this investigation, all krypton secondary standards [1] which are represented by transitions of $1 s-n p$ type, and the 1934 interference measurements by Meggers and Humphreys [2] of lines not included in the first two groups. The third group, consisting mostly of infrared, had been determined relative both to cadmium and neon. An average was adopted for use in this array. A considerable number of $1 s-n p$ transitions give lines too faint for interference measurements. For the sake of completeness, these are included in the table, the values being given by the latest National Bureau of Standards grating observations [15]. As in the previous cases, the term values have been adjusted to give the best conformity to the entire set of interference observations. The relative accuracy of the ultraviolet determinations compares favorably either with that of the secondary standards or the group of infrared lines.

Calculated values of wave numbers in the inaccessible infrared region are shown in parentheses.

Attention is called to a similar array published in 1930 [8] using the measurements then available, but not including ultraviolet data. It will be seen that the changes due to repeated measurements of increased precision are practically negligible. 
TABLE 6.-Krypton $I$ array of $1 s-n p$ combinations

\begin{tabular}{|c|c|c|c|c|c|c|c|c|c|}
\hline $\begin{array}{l}\text { Term } \\
\text { symbol } \\
\downarrow\end{array}$ & & $\begin{array}{l}\text { Term } \\
\text { value } \\
\downarrow\end{array}$ & $\begin{array}{c}18_{2} \\
j=1 \\
27068.199\end{array}$ & $\begin{array}{c}\text { Diff. } \\
655.087\end{array}$ & $\begin{array}{c}1 s_{3} \\
0 \\
27723.286\end{array}$ & $\begin{array}{c}\text { Diff. } \\
4274.853\end{array}$ & $\begin{array}{c}1 s_{4} \\
1 \\
31998.139\end{array}$ & $\begin{array}{c}\text { Diff. } \\
945.026\end{array}$ & $\begin{array}{c}18_{5} \\
2 \\
32943.165\end{array}$ \\
\hline $\begin{array}{l}5 \mathrm{~T} \\
5 \mathrm{X}\end{array}$ & $\begin{array}{l}3 \\
1\end{array}$ & $\begin{array}{l}4411.655 \\
4434.138\end{array}$ & $\stackrel{*}{*}{ }_{22634 .} 061$ & & $\begin{array}{c}* \\
23289.16\end{array}$ & & $\stackrel{*}{*}$ & & $\begin{array}{l}28531.510 \\
28509.04\end{array}$ \\
\hline $5 Z$ & 2 & 4443.763 & 22624.437 & & (9.148) & & 27554. 376 & & 28449.45 \\
\hline $5 p_{5}$ & 0 & 3618.703 & 23449. 496 & & * & & 28379. $\begin{array}{r} \pm 0 \\
436 \\
+0\end{array}$ & & * \\
\hline $5 p_{6}$ & 2 & 3753.938 & 23314. $\begin{array}{c} \pm 0 \\
.25\end{array}$ & & - & & 28244. $\begin{array}{c} \pm 0 \\
204\end{array}$ & 945.020 & 29189. 224 \\
\hline $5 p_{7}$ & 1 & 3765. 199 & & & 23957.82 & & 28232.940 & & $\begin{array}{c}29177.92 \\
(7.966)\end{array}$ \\
\hline $\begin{array}{l}5 p_{9} \\
5 p_{10}\end{array}$ & $\begin{array}{l}3 \\
1\end{array}$ & $\begin{array}{l}3811.594 \\
3832.120\end{array}$ & $\begin{array}{c}{ }^{*} \\
23236.081 \\
-2\end{array}$ & 655.083 & $\begin{array}{c}\text { 23891. } 164 \\
+2\end{array}$ & & $\begin{array}{c}* \\
28165.44 \\
(6.019)\end{array}$ & & $\begin{array}{r}29111.571 \\
29111.037 \\
+8\end{array}$ \\
\hline${ }_{4 \mathrm{X}}^{4 \mathrm{~T}}$ & $\begin{array}{l}3 \\
1\end{array}$ & $\begin{array}{l}6894.043 \\
6950.442\end{array}$ & 20117. 72 & & 20772.843 & 4274.856 & 25047.699 & & $\begin{array}{l}26049.122 \\
25992.88\end{array}$ \\
\hline $4 \mathrm{Y}$ & 2 & 6893. 275 & $\begin{array}{c}(7.757) \\
20174.92 \\
(4.924)\end{array}$ & & +1 & & $\begin{array}{r}-2 \\
25104.862 \\
+2\end{array}$ & 945.030 & $\begin{array}{r}(2.723) \\
26049.892 \\
-2\end{array}$ \\
\hline $4 Z$ & 2 & 6949. 321 & $\begin{array}{l}20118.85 \\
(8.878)\end{array}$ & & * & & $\begin{array}{r}25048.818 \\
+0\end{array}$ & 945.027 & 25993. 845 \\
\hline $4 p_{5}$ & 0 & 5504. 509 & 21563.65 & & * & & 26493.630 & & $*^{-1}$ \\
\hline $4 p_{6}$ & 2 & 5668. 201 & 21399.92 & & * & & 26329.938 & 945.025 & 27274.963 \\
\hline $4 p_{\eta}$ & 1 & 5693. 555 & $\begin{array}{r}21374.53 \\
(4.644)\end{array}$ & & $\begin{array}{l}22029.69 \\
(9.731)\end{array}$ & & $\begin{array}{l}26304.584 \\
\pm 0\end{array}$ & 945.025 & $\begin{array}{r}27249.609 \\
+1\end{array}$ \\
\hline $4 p_{8}$ & 2 & 5774. 089 & $\begin{array}{c}(4.644) \\
21294.04\end{array}$ & & $(9.71)$ & & 26224. 049 & 945.029 & 27169. 078 \\
\hline $\begin{array}{l}4 p_{9} \\
4 p_{10}\end{array}$ & $\begin{array}{l}3 \\
1\end{array}$ & $\begin{array}{l}5773.717 \\
5909.516\end{array}$ & $\begin{array}{c}(4.010) \\
21158.61 \\
28\end{array}$ & & * & & & & $\begin{array}{r}27169.448 \\
27033.649\end{array}$ \\
\hline $\begin{array}{l}3 p_{1} \\
3 p_{2}\end{array}$ & $\underset{2}{0}$ & $\begin{array}{l}4093.318 \\
4347.117\end{array}$ & $\begin{array}{l}22974.881 \\
22721.082 \\
\end{array}$ & & * & & 27651.022 & 945.027 & $\begin{array}{c}* \\
28596.049\end{array}$ \\
\hline $3 p_{3}$ & 1 & 4400.701 & 22667. $\begin{array}{r} \pm 0 \\
498\end{array}$ & 655.087 & 23322.585 & & 27597. 18 & & 28542.461 \\
\hline $3 p_{4}$ & 1 & 4476.626 & 22591. $\begin{array}{l} \pm 0 \\
573 \\
+0\end{array}$ & 655.087 & $\begin{array}{r}23246 . \quad \begin{array}{l} \pm 0 \\
+0\end{array} \\
+0\end{array}$ & 4274.852 & $\begin{array}{l}4501.512 \\
+1\end{array}$ & 945.021 & 28466. 533 \\
\hline $3 p_{5}$ & 0 & 9153. 254 & 17914.93 & & & & 22844.885 & & \\
\hline $3 p_{6}$ & 2 & 9552. 275 & $\begin{array}{c}(45.945) \\
17515.93\end{array}$ & & * & & 22445.864 & 945.026 & 23390.890 \\
\hline $3 p_{7}$ & 1 & 9601. 416 & 17466.81 & & 18121. 89 & & 22396. $\begin{array}{l} \pm 0 \\
723\end{array}$ & 945.025 & 23341. 748 \\
\hline $3 p_{8}$ & 2 & 9793. 947 & $\begin{array}{l}17274.47 \\
(4.252)\end{array}$ & & 1.0 & & 22204. $\begin{array}{l}592 \\
+0\end{array}$ & 945.027 & 23149. 419 \\
\hline $\begin{array}{l}3 p_{9} \\
3 p_{10}\end{array}$ & $\begin{array}{l}3 \\
1\end{array}$ & $\begin{array}{r}9799.251 \\
10027.698\end{array}$ & 17040.53 & & $\stackrel{*}{*} 17695.585$ & 4274.856 & 21970.441 & 945.029 & $\begin{array}{l}23143.914 \\
22915.470\end{array}$ \\
\hline $2 p_{1}$ & 0 & 14059.829 & 13008.370 & & & & 17938. $\frac{ \pm 0}{27}$ & & \\
\hline $2 p_{2}$ & 2 & 14969.730 & $\begin{array}{r}12098.469 \\
\pm 0\end{array}$ & & * & & $\begin{array}{r}17028.409 \\
\pm 0\end{array}$ & 945.027 & 17973. 436 \\
\hline $2 p_{3}$ & 1 & 14995. 749 & 12072.450 & 655.087 & 12727.537 & & 17002. 42 & & 17947.417 \\
\hline $2 p_{4}$ & 1 & 15318. 982 & 11749. $\frac{ \pm 0}{218}$ & 655.087 & 12404. $\begin{array}{l} \pm 0 \\
305\end{array}$ & 4274. 852 & 16679. 157 & 945.025 & 17624. 182 \\
\hline $\begin{array}{l}2 p_{s} \\
2 p_{6}\end{array}$ & $\begin{array}{l}0 \\
2\end{array}$ & $\begin{array}{l}\text { 18822. } 038 \\
19791.560\end{array}$ & $\begin{array}{l}(8246.161) \\
(7276.639)\end{array}$ & & & & $\begin{array}{l}13176.101 \\
12206.579\end{array}$ & 945.027 & $\stackrel{*}{*}^{*}$ \\
\hline $2 p_{7}$ & 1 & 19950.506 & (7117. 693) & & $(7772.780)$ & & 12047.633 & 945.026 & 12992.659 \\
\hline $2 p_{8}$ & 2 & 20607. 523 & $(6460.673)$ & & * & & $11390 . \frac{ \pm 0}{616}$ & 945.027 & 12335. $\begin{array}{c} \pm 0 \\
643\end{array}$ \\
\hline $\begin{array}{l}2 p_{9} \\
2 p_{10}\end{array}$ & $\begin{array}{l}3 \\
1\end{array}$ & $\begin{array}{l}20620.501 \\
21746.387\end{array}$ & ${ }_{(5321.812)}^{*}$ & & $\stackrel{*}{*}$ & & $\begin{array}{r}* 0 \\
10251.751 \\
+1\end{array}$ & 945.027 & $\begin{array}{r}-1 \\
12322.664 \\
11196.778 \\
\pm 0\end{array}$ \\
\hline
\end{tabular}




\section{REFERENCES}

[1] Trans. Int. Astron. Union 5, 86-87 (1935).

[2] W. F. Meggers and C. J. Humphreys, J. Research NBS 13, 293-307 (1934) RP710.

[3] W. F. Meggers and C. J. Humphreys, BS J. Research 10, 436-447 (1933) RP540.

[4] F. Paschen, Ann. Phys. 60, 405-453 (1919).

[5] C. V. Jackson, Phil. Trans. Roy. Soc. A236, 1 (1936).

[6] R. Ritschl and H. Schober, Physik. Z. 38, 6-9 (1937).

[7] Trans. Int. Astron. Union 5, 301 (1935).

[8] C. J. Humphreys, BS J. Research 5, 1044 (1930) RP245.

[9] H. Margenau and W. W. Watson, Phys. Rev. 52, 384 (1937).

[10] C. Fabry and H. Buisson, Astrophys. J. 28, 169-196 (1908).

[11] W. F. Meggers and C. J. Humphreys, J. Research NBS 18, 543-557 (1937) RP992.

[12] W. F. Meggers, BS Sci. Pap. 12, 198-205 (1915) S251.

[13] W. F. Meggers and C. G. Peters, BS Sci. Pap. 14, 724 (1918) S327.

[14] K. W. Meissner, Z. Physik 39, 172-190 (1926).

[15] W. F. Meggers, T. L. deBruin, and C. J. Humphreys, BS J. Research 7, 643-657 (1931) RP364.

[16] W. F. Meggers, BS Sci. Pap. 17, 193-202 (1921) S414.

Washington, November 16, 1937. 